\title{
Smart homes for older people involved in rehabilitation activities - reality or dream, acceptance or rejection?
}

Adela-Viviana Sitar-Taut ${ }^{1}$, Dan-Andrei Sitar-Taut ${ }^{2}$, Oana Cramariuc ${ }^{3}$, Vasile Negrean ${ }^{1}$, Dorel Sampelean ${ }^{1}$, Lucia Rusu' ${ }^{2}$, Olga Orasan ${ }^{1}$, Adriana Fodor ${ }^{1}$, Gabriela Dogaru'${ }^{1}$, Angela Cozma ${ }^{1}$

Corresponding author: Sitar-Taut Dan-Andrei, E-mail address: dan.sitar@econ.ubbcluj.ro

1"Iuliu Haţieganu" University of Medicine and Pharmacy, Cluj-Napoca, Romania 2“Babes-Bolyai” University, Faculty of Economics and Business Administration, Department of Business Information Systems,

3 IT Center for Science and Technology, Bucharest, Romania

\begin{abstract}
Introduction Recent statistics show an increase in the prevalence of the elderly population. The year 2012 was declared European Year for Active Ageing and Solidarity between Generations, and the European Commission launched campaigns like The Active and Assisted Living Joint Program (AAL JP). Rehabilitation in the elderly is a desideratum, but the problems of rehabilitation in the elderly are numerous. The aim of the study was to evaluate degree of acceptance/implementation of different technologies in Romania, of monitoring in the rehabilitation activity conducted at home. Material and methods the study comprised 154 persons with a mean age of $73.37 \pm 7.33$ years, of which 64 (41.6\%) male and 90 (58.4\%) female. All subjects completed a questionnaire regarding the living conditions and health status, about the degree of acceptance of intelligent technologies for monitoring current health status/reporting acute events. Results $18.2 \%$ used the Internet frequently, and the rest used it almost never or rarely. $71.9 \%$ of patients agreed to wear a portable sensor ( $\mathrm{p}=0.07$ between men and women), 33.1\% accepted videocam, $47.4 \%$ accepted a screen, $41.3 \%$ accepted living room monitoring, $68 \%$ sensor in the room on the wall and $69.1 \%$ accepted fall detection sensor. No significant differences were found regarding the acceptance vs rejection of personal sensors, living room monitoring, sensors in the room, fall detection sensors depending on the gender, income level, type of caregiving. Using of videocam and screen was influenced by type of care giving and income $(\mathrm{p}=0.002, \mathrm{p}<0.001$, respectively for screen $\mathrm{p}=0.032$ and $\mathrm{p}=0.003)$. In conclusion, Romanian old people are not keen on using intelligent devices for health status related to acute event monitoring. More programs and measures are needed for device implementation in real life.
\end{abstract}

Key words: smart homes, elderly, acceptance, Romania

\section{Introduction}

Recent statistics show an increase in the prevalence of the elderly population [1,2,3] ,with more than $20 \%$ of the European Union population reaching over 65 years of age by 2025. Life expectancy of old people has increased. The prevalence of chronic, disabling diseases (cardiovascular diseases, diabetes mellitus, ophthalmological, neurological, locomotor, mental, chronic disorders, etc.) increases with aging.

The year 2012 was declared European Year for Active Ageing and Solidarity between Generations, and the European Commission launched campaigns like The Active and Assisted Living Joint Program (AAL JP), aimed at the development of e-health or m-health technologies, in order to ensure a dignified life to these people, with an adequate quality of life in a familiar habitat, without giving up the desideratum of personal independence - smart homes.

With aging, patients become sedentary (in USA, about $65 \%$ of the elderly are sedentary [4], which favors overweight and obesity, the hypokinetic phenomenon. Cardiac changes occur even in the early phases of weight gain, with an alteration of systolic and diastolic functions [5-8]. Elderly people are encouraged to respect the principles of a healthy life
- diet with the respect of the principles of modern nutrition, to perform physical exercise [9]. There is currently no need to mention the benefits of physical exercise, which is responsible for the maintenance of adequate weight, the fight against some disorders, post-event recovery, an increase in the quality of life [10].

Rehabilitation in the elderly is a desideratum, being indicated in patients post-myocardial infarction, patients with heart failure, peripheral arterial diseases, valvular diseases, after cardiac or noncardiac surgery, patients with diabetes, neurological disorders or any kind of other diseases.[11-15]. The structure and content of medical training should be adapted to the characteristics of elderly persons. The application of rehabilitation programs allows obtaining a better control of blood pressure values [16], increasing functional capacity $[17,18]$. Recent studies also show the fact that rehabilitation at home is effective, but requires continuous monitoring. $[19,20]$. However, the problems of rehabilitation in the elderly are numerous, given the reduced availability of these persons, their diminished mobilization capacity, and the need for careful monitoring during the rehabilitation program. 
Over the past years, the foundations of gerontechnology, the symbiotic science between gerontology and technology, have been laid [21,22]. Ambient assistive living technology (AAL) represents solutions that improve the lives of the elderly, support elderly/disabled people in carrying out daily activities [21,23], in reducing falls, disability, stress, fear or social isolation [24], in living independently in their own homes [3], in recovering after various events. The AAL Joint Programme was co-financed by the European Commission and the following 22 Partner States: Austria, Belgium, Cyprus, Denmark, Finland, France, Germany, Hungary, Ireland, Israel, Italy, Luxembourg, the Netherlands, Norway, Poland, Portugal, Romania, Slovenia, Spain, Sweden, Switzerland and the United Kingdom.

Systems have been currently developed and implemented which use smart phones, tablets, smart TVs, wearable or wireless technologies (sensors, bracelets) to monitor the activities of elderly persons - administration of medication, performance of the indicated physical exercises, occurrence of acute events (falls from the same level, acute cardiovascular events) - Health@Home, Ageing in Balance, MedReminder, DietAdvice.

Recent studies have shown the fact that a large proportion of elderly persons are, at least at first, reluctant to accept advanced technologies, even if theoretically they recognize their benefits $[25,26]$ and progress of the society [25].

The reasons invoked include: distrust in one's own ability to use these new technologies [25,27,28,29], cognitive personal barriers [30], higher technology anxiety [28,31,32, 33], no trust in devices [3] or, the most important one, loss of privacy[3].

Also, aspects related to website design, the presentation of visual information, decreased performance in spatial orientation are barriers to its use $[3,25,27,28,29,34]$. Difficulties related to the use of the Internet and the fact that elderly persons have a different approach to the Internet-based technology compared to young persons should also be mentioned [22].

In Romania, the great majority of the population uses the Internet to search for information, news, to make electronic payments. A small proportion possess extensive competencies. In general, devices and applications for blood pressure, glycemia, drug administration monitoring are accepted
(BloodPressure Meter, DiabeticMonitor, Thermometer, Glucometer, PulseOximeter, MedReminder). Even if Romania has adhered to the initiatives launched by the European Union, there are no studies on the degree of acceptance/implementation of these technologies in our country, on the acceptance of monitoring in the rehabilitation activity conducted at home.

The aim of the study was to evaluate these aspects of the life of elderly persons in Romania.

\section{Material and methods}

The study comprised 154 persons with a mean age of $73.37 \pm 7.33$ years, of which $64(41.6 \%)$ male and 90 (58.4\%) female.

All subjects completed a questionnaire regarding the living conditions and health status. The questions included in the questionnaire also required information related to the degree of acceptance of intelligent technologies for monitoring current health status/reporting acute events. The relationship between different characteristics of the subjects and the degree of acceptance of the technologies was assessed.

Statistical analysis was carried out using the SPSS for Windows (v 16.0, IBM Corporation, Armonk, NY, USA) and MedCalc (v 10.3.0.0, MedCalc Software, Ostend, Belgium) software programs. The Kolmogorov- Smirnov test was used to assess the normal distribution of continuous numerical variables. Mean and standard deviation were used for numerical variables' characterization. Categorical variables were presented as number and percentage. Data were comparated using Student/ MannWhitney/ $\chi 2$ test depending on variable type.

A value of $p$ less than 0.05 was considered statistically significant. The selected patients were informed about the study protocol. All subjects gave their signed informed consent.

The study was carried out in agreement with The Code of Ethics of the World Medical Association (Declaration of Helsinki) for experiments involving humans.

\section{Results}

The characteristics of the patients are presented in Table 1. 
A proportion of $56.5 \%$ had no need for caregiving, $34.4 \%$ received non-permanent care and $7.1 \%$ benefited from permanent caregiving. In case of emergency, most of the emergency caregivers were represented by friends or relatives; only $1.9 \%$ of the cases had a dedicated caregiver. In most of the cases, the caregiver was not specialized. $1.3 \%$ of the patients self-estimated the living conditions as bad, $7.8 \%$ as poor, $46.8 \%$ as decent, $33.1 \%$ as good, and the rest as very good.

The most prevalent comorbidities were represented by cardiovascular diseases, hypertension, diabetes, neurological and osteoarticular dysfunction.

18.2\% used the Internet frequently, and the rest used it almost never or rarely (reasons - lack of time, means, skills, and interest).

We evaluated the degree of acceptance, depending on both personal characteristics and technology type:

$71.9 \%$ of patients agreed to wear a portable sensor, ( $\mathrm{p}=0.07$ between men and women);

$33.1 \%$ accepted videocam with no significant differences between sexes $(\mathrm{p}=0.8)$;

$47.4 \%$ accepted a screen with no significant differences between sexes $(\mathrm{p}=0.8)$;

$41.3 \%$ accepted living room monitoring with no significant differences between sexes $(\mathrm{p}=0.9)$;

$68 \%$ accepted sensor in the room, on the wall with no significant differences between sexes $(\mathrm{p}=0.3)$;

$69.1 \%$ accepted fall detection sensor with no significant differences between sexes $(p=0.4)$. Complete data are presented in figure 1.

The acceptance of different kinds of technology was assessed depending on the gender, income level, and type of caregiving - Table 2. No significant differences were found regarding the acceptance vs rejection of personal sensors, living room monitoring, sensors in the room, fall detection sensors.

The relationship (evaluated as correlation coefficient) between technology acceptance and personal and demographic features is presented in Table $\mathbf{3}$ (only the significance level of the relationship).

The main reasons for system rejection were represented by fear of losing the device, perception of no need, and privacy concerns. Less than $50 \%$ of the patients considered the mobile phone, notebook or tablet easy to use, pleasant.

\section{Discussion}

There are currently several European Union programs and directives that support the development of modern methods and applications assisting the elderly. Thus, SOPRANO projects - Service-Oriented Programmable Smart Environments for Older Europeans and the NITICS Project within the AAL Program (Network Infrastructure for Innovative Home Care Solutions) [35] have developed modern monitoring systems supporting elderly persons, based on AAL concepts, by using advanced IT techniques to preserve the independence of the elderly. OLDES [36] represents an EU co-funded project under the IST Program, which contains a module intended for the clinical monitoring of elderly people - the implemented technical solutions being easy to use, inexpensive, and adapted to the profile of the monitored person. HERA (Home sERvices for specialized elderly Assisted living) is a platform for persons with Alzheimer's disease [37] and the SPES proposal for the November 4 geographical contexts (Ferrara, Vienna, Brno and Kosice) [38] is focused on patients with disabilities, respiratory disorders and dementia.

In the context of the development of these programs, many authors draw attention to the benefits of the use by elderly persons of intelligent applications and systems in daily life, one of the most useful applications being represented by blood pressure, pulse, oxygen level monitoring $[39,40]$. However, a current priority is the use of these data and systems not only in a static manner (in punctual moments), but their use for monitoring, programming and adjusting the rehabilitation exercises performed at home, for reporting medical emergencies of any kind $[39,40]$.

Even if the elderly have a positive approach to technology, the extent to which they actually use it, their interest in its use are reduced at international level [25, 29, 41, 42] and while few studies on elderly persons are available, this age category being frequently neglected [25].

As we mentioned before, this study aimed to evaluate the degree of acceptance of monitoring systems by Romanian elderly persons. Its results were similar to those of the literature, the reasons invoked partially overlapping those reported in other studies. If in the current study, the most important reasons for their rejection were the fear of losing the device and the lack of awareness of their necessity, which were followed by the fear of losing privacy, other studies recognize the last reason as being the most important. 
At the same time, the degree of acceptance was significantly influenced by the type of care received by patients at home and by their financial level (similar data to those of the literature [27,41], which evidences the fact that the cost of the device is decisive for acceptance).

There were also significant differences between the two sexes, women generally being more permissive to the "intrusion" of devices into their habitat.

As other studies suggest [3], education measures and public policies for elderly persons are needed to overcome these barriers.

The low degree of acceptance of modern systems for the monitoring of rehabilitation activity in Romania requires (at least for the time being) finding alternative solutions - the use of smart phones or possibly tablets. Given that Romania ranks second in the EU in terms of Internet speed, monitoring of the elderly can be, at least theoretically, most successfully achieved using mobile devices (iPhones, tablets) [43]. As far as we know, the Mobile@old platform represents one of the first systems developed in our country for monitoring the elderly, ensuring their surveillance in their own homes (during daily activities) [2]. At the same time, its particularity is that using an interdisciplinary approach (based on new artificial intelligence, image analysis, knowledge extraction, data fusion techniques combined with medical knowledge), it will achieve monitoring in a minimally invasive way [2].

Mobile@Old project represented an m-health approach, whose main purpose was to develop the necessary instruments (wearable technologies) to assist elderly persons in performing physical exercises, with the monitoring of blood pressure, heart rate values, thus acting as a personal assistant [44].

In conclusion, Romanian old people are not keen on using intelligent devices for health status related to acute event monitoring. More programs and measures are needed for device implementation in real life.

Acknowledgement this paper is supported by national project Mobile@Old, PN-II-PT-PCCA2013-4-2241 No. 315/2014, under the Partnerships Program PN II, funded by MEN - UEFISCDI.

Figure 1 - Devices’ degree of acceptance

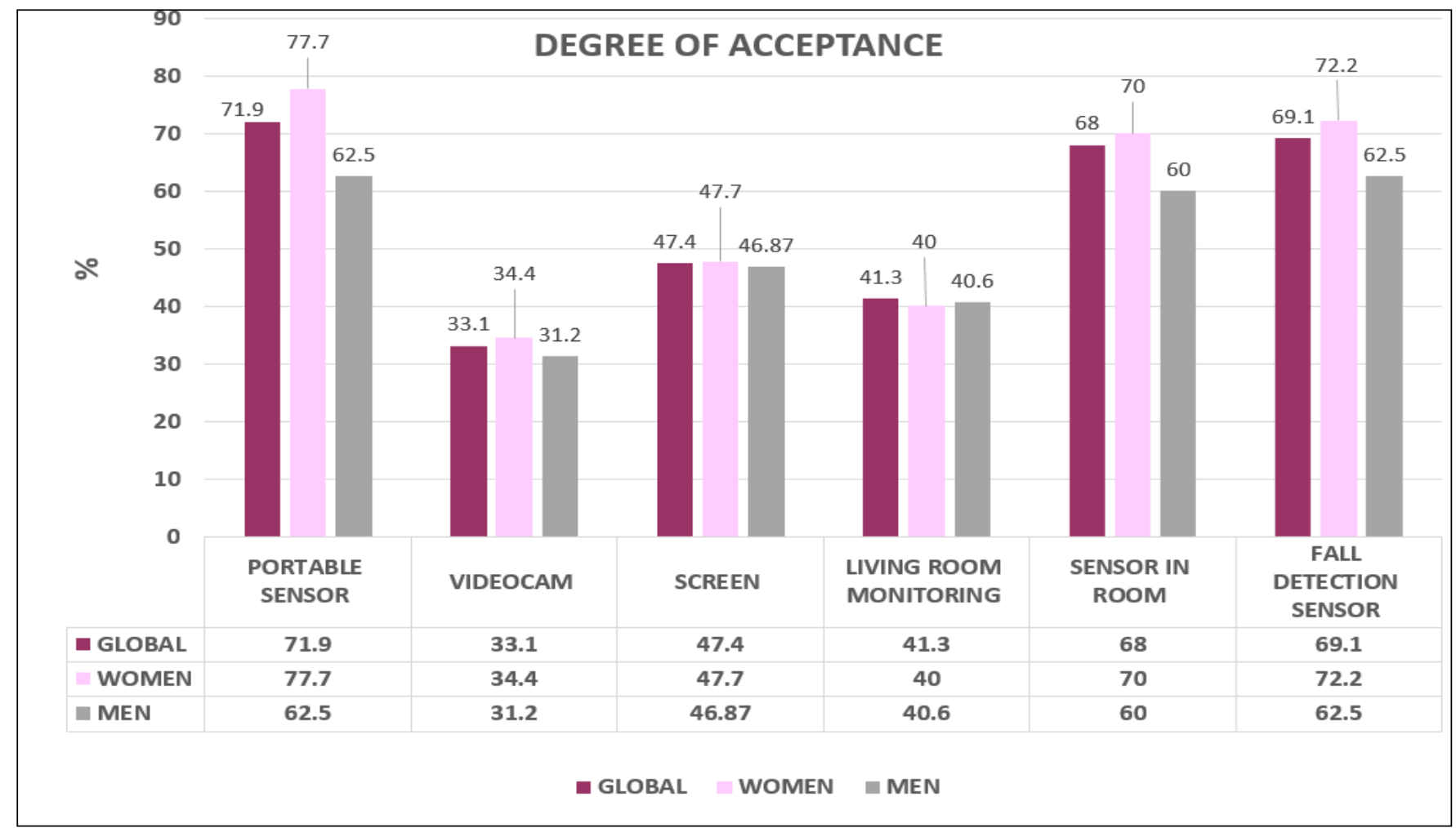


Table 1 - Patients' characteristics

\begin{tabular}{|c|c|c|c|c|c|c|}
\hline & & & Global 154 & Men & Women & $\mathrm{p}$ \\
\hline Age & Mean \pm SD & & $73.37 \pm 7.33$ & $74.95 \pm 7.13$ & $72.21 \pm 7.22$ & 0.02 \\
\hline Gender & No (\%) & & $154(100)$ & $64(41.6)$ & $90(58.4)$ & \\
\hline \multirow[t]{2}{*}{ Living } & No (\%) & House & $76(49.4)$ & 37 (57.81) & 39 (43.33) & 0.1 \\
\hline & & Flat & $78(50.6)$ & 27 (42.18) & $51(56.66)$ & \\
\hline \multirow[t]{4}{*}{ Caregiving } & No (\%) & None & 87 (56.5) & $31(48.43)$ & $56(62.22)$ & \\
\hline & & Non-permanent & $53(34.4)$ & $26(40.6)$ & $27(30)$ & \\
\hline & & Permanent & $11(7.1)$ & $6(9.3)$ & $5(5.55)$ & \\
\hline & & No response & $3(1.9)$ & $1(1.5)$ & $2(2.22)$ & 0.3 \\
\hline \multirow[t]{3}{*}{ Type of caregivers } & No (\%) & Non specialized & $52(33.8)$ & 23 (35.9) & $29(32.22)$ & 0.12 \\
\hline & & Specialized & $14(9.1)$ & $9(14)$ & $5(5.55)$ & \\
\hline & & No response & $88(57.14)$ & $32(50)$ & $56(62.22)$ & \\
\hline \multirow{2}{*}{$\begin{array}{l}\text { Chronically } \\
\text { condition }\end{array}$} & No (\%) & Yes & 103(66.9) & $41(64)$ & $62(68.8)$ & 0.5 \\
\hline & & No & $51(33.11)$ & $23(36)$ & $28(31.1)$ & \\
\hline \multirow[t]{6}{*}{ Income range } & No (\%) & $<=100$ euro & $1(0.6)$ & $0(0)$ & $1(1.11)$ & 0.68 \\
\hline & & $101-500$ & $66(42.9)$ & $28(43.75)$ & $38(42.22)$ & \\
\hline & & $501-1000$ & $58(37.7)$ & $21(32.8)$ & 37 (41.11) & \\
\hline & & $1001-2000$ & $15(9.7)$ & $8(12.5)$ & $7(7.77)$ & \\
\hline & & $>2000$ & $3(1.9)$ & $2(3.12)$ & $1(1.11)$ & \\
\hline & & No response & $11(7.1)$ & $5(7.8)$ & $6(6.66)$ & \\
\hline
\end{tabular}

Table 2 - Devices’ acceptance depending of type of care giving and, respectively, income

\begin{tabular}{|l|l|c|c|l|}
\hline Videocam & & \multicolumn{2}{|c|}{ Acceptance } & p \\
\hline & & No & yes & \\
\hline & Type of care giving- specialized & $3.9 \%$ & $19.6 \%$ & 0.002 \\
\hline & Income - 100-500 euro & $50 \%$ & $27.45 \%$ & $<0.001$ \\
\hline Screen & & \multicolumn{2}{|c|}{ Acceptance } & p \\
\hline & & No & yes & \\
\hline & Type of care giving- specialized & $5.2 \%$ & $15.06 \%$ & 0.032 \\
\hline & Income - 100-1000 euro & $80 \%$ & $69 \%$ & 0.003 \\
\hline
\end{tabular}


Table 3- The relationships between personal characteristics - devices' type- degree of acceptance

\begin{tabular}{|c|c|c|c|c|}
\hline Type of technology & Variable & $\begin{array}{l}\text { Global } \\
\text { p }\end{array}$ & $\begin{array}{l}\text { Male } \\
\text { p }\end{array}$ & $\begin{array}{l}\text { Women } \\
\mathrm{p}\end{array}$ \\
\hline \multirow[t]{6}{*}{ Personal sensor } & Living & 0.83 & 0.47 & 0.59 \\
\hline & Permanent careging & 0.26 & 0.66 & 0.28 \\
\hline & Type of caregiving & 0.37 & 0.42 & 0.28 \\
\hline & Income & 0.17 & 0.25 & 0.12 \\
\hline & Chronically condition & 0.45 & 0.42 & 0.85 \\
\hline & Age & 0.20 & 0.12 & 0.85 \\
\hline \multirow[t]{6}{*}{ Video cam } & Living & 0.034 & 0.55 & 0.03 \\
\hline & Permanent careging & 0.9 & 0.6 & 0.7 \\
\hline & Type of caregiving & 0.002 & 0.05 & 0.01 \\
\hline & Income & $<0.0001$ & 0.011 & 0.0043 \\
\hline & Chronically condition & 0.8 & 0.15 & 0.49 \\
\hline & Age & 0.09 & 0.5 & 0.07 \\
\hline \multirow[t]{6}{*}{ Living room monitoring } & Living & 0.11 & 0.6 & 0.13 \\
\hline & Permanent careging & 0.75 & 0.2 & 0.7 \\
\hline & Type of caregiving & 0.01 & 0.038 & 0.06 \\
\hline & Income & 0.09 & 0.2 & 0.19 \\
\hline & Chronically condition & 0.25 & 0.07 & 0.8 \\
\hline & Age & 0.07 & 0.6 & 0.04 \\
\hline \multirow[t]{6}{*}{ Sensor in the room } & Living & 0.5 & 0.7 & 0.58 \\
\hline & Permanent careging & 0.5 & 0.3 & 0.59 \\
\hline & Type of caregiving & 0.3 & 0.29 & 0.32 \\
\hline & Income & 0.29 & 0.63 & 0.54 \\
\hline & Chronically condition & 0.08 & 0.13 & 0.5 \\
\hline & Age & 0.75 & 0.7 & 0.8 \\
\hline \multirow[t]{6}{*}{ Falling detection sensor } & Living & 0.6 & 0.96 & 0.29 \\
\hline & Permanent careging & 0.05 & 0.22 & 0.12 \\
\hline & Type of caregiving & 0.13 & 0.22 & 0.15 \\
\hline & Income & 0.19 & 0.7 & 0.28 \\
\hline & Chronically condition & 0.47 & 0.25 & 0.9 \\
\hline & Age & 0.96 & 0.66 & 0.9 \\
\hline \multirow[t]{6}{*}{ Screen } & Living & 0.26 & 0.85 & 0.12 \\
\hline & Permanent careging & 0.69 & 0.16 & 0.9 \\
\hline & Type of caregiving & 0.032 & 0.14 & 0.05 \\
\hline & Income & 0.003 & 0.06 & 0.023 \\
\hline & Chronically condition & 0.20 & 0.29 & 0.59 \\
\hline & Age & 0.12 & 0.55 & 0.13 \\
\hline
\end{tabular}




\section{Bibliography}

1. Eurostat 2010 - http://ec.europa.eu/eurostat/web/esa2010

2. Rusu L., Jecan S., Sitar D. (2015) Mobile@Old an ADL Solution. In: Abramowicz W. (eds) Business Information Systems Workshops. BIS 2015. Lecture Notes in Business Information Processing, vol 228. Springer, Cham

3. Fischer SH, Daniel David D, Crotty BH, Dierks M, Safran C. Acceptance and Use of Health Information Technology By Community-Dwelling Elders. Int J Med Inform. 2014; 83(9): 624-635.

4. Chao, Ying-Yu. "Exergaming: therapeutic benefits in older adults”, June 2015, http://lermagazine.com/article/exergamingtherapeuticbenefits-in-older-adults.

5. Alexescu T, Cozma A, Sitar-Taut A, Negrean V, Handru MI, Motocu M, Tohanean N, Lencu C, Para I. Cardiac Changes in Overweight and Obese Patients. Rom J Intern Med., 2016, 54, 3, 161-172.

6. Goidescu CM, Farcas AD, Anton FP, Vida-Simiti LA. The Pattern of Ventricular Remodeling Influences the Level of Oxidative Stress in Heart Failure Patients. Rev Chim (Bucharest). 2017; 68(7): 1506-1511.

7. Farcas AD, Stoia MA, Anton FP, et al. The Lymphocyte Count and Neutrophil/lymphocyte Ratio are Independent Predictors for Adverse Cardiac Events in Ischemic Heart Failure but not with Non-ischemic Heart Failure. Rev Chim.2016;67(10):2091-2094.

8. Mocan M, Anton F, Suciu S, Rahaian R, Blaga SN, Farcas AD. Multimarker assessment of diastolic dysfunction in metabolic syndrome patients. Metabolic Syndrome and Related Disorders. 2017;15(10): 507514.

9. Stula S. Living in Old Age in Europe - Current Developments and Challenges”. Working Paper No. 7 of the Observatory for Sociopolitical Developments in Europe, June 2012.

10. Zdrenghea $\mathrm{D}$ et al. Recuperare si preventie cardiovasculara. Ed Clusium 2008. ISBN 978-973555-576-4.

11. Baumgartner H, Falk V, Bax JJ, De Bonis M, Hamm C et all. 2017 ESC/EACTS Guidelines for the management of valvular heart disease. Euro H Journal 2017; 38:2739-2791.

12. Victor Aboyans V, Ricco JB, Bartelink ML, Björck M, Brodmann M, Cohnert T et all. 2017 ESC Guidelines on the Diagnosis and Treatment of Peripheral Arterial Diseases, in collaboration with the European Society for Vascular Surgery (ESVS): Document covering atherosclerotic disease of extracranial carotid and vertebral, mesenteric, renal, upper and lower extremity arteries. Endorsed by: the European Stroke Organization (ESO. The Task Force for the Diagnosis and Treatment of Peripheral Arterial Diseases of the European Society of Cardiology (ESC) and of the European Society for Vascular Surgery (ESVS). European Heart Journal. 2018;39(9):763-816.
13. Ibanez B, James S, Agewall S, Antunes MJ, Bucciarelli-Ducci C, Bueno $\mathrm{H}$ et all. 2017 ESC Guidelines for the management of acute myocardial infarction in patients presenting with ST-segment elevation: The Task Force for the management of acute myocardial infarction in patients presenting with STsegment elevation of the European Society of Cardiology (ESC). European Heart Journal. 2018;39(2):119-177.

14. Ponikowski P, Voors AA, Anker SD, Bueno H, Cleland JGF, Coats AJS et all. 2016 ESC Guidelines for the diagnosis and treatment of acute and chronic heart failure: The Task Force for the diagnosis and treatment of acute and chronic heart failure of the European Society of Cardiology (ESC). Developed with the special contribution of the Heart Failure Association (HFA) of the ESC.European Heart Journal, 2016; 37(27):2129-2200.

15. Fodor A, Cozma A, Karnieli E. TBC update: personalized epigenetic management of diabetes. Personalized Medicine. 2017;14(6):531-549.

16. Kolbe-Alexander TH, Lambert EV, Charlton KZ. Effectiveness of a community based low intensity exercise program for older adults. J Nutr Health Aging 2006; 10:21-29.

17. Hanna IR, Wenger NK. Secondary prevention of coronary heart disease in elderly patients. Am Fam Physician 2005;71(12):2289-2296.

18. Galizia G, Balestrieri G, De Maria B, La Storia C, Monelli M, Salvaderi S, Romanelli G, Dalla Vecchia LA. Role of rehabilitation in the elderly after an acute event: insights from a real-life prospective study in the sub-acute care setting. Eur J Phys Rehabil Med. 2018 Jun 11. [Epub ahead of print].

19. Oerkild B, Frederiksen M, Hansen JF, Simonsen L, Skovgaard LT, Prescott E. Home-based cardiac rehabilitation is as effective as centre-based cardiac rehabilitation among elderly with coronary heart disease: results from a randomised clinical trial. Age Ageing. 2011;40(1):78-85.

20. Taylor RS, Dalal H, Jolly K, Moxham T, Zawada A. Home-based versus centre-based cardiac rehabilitation. Cochrane Database Syst Rev. 2010; 20(1):1. Art. No.: CD007130. DOI: 10.1002/14651858.CD007130.pub2.

21. Jecan S, Benta D, Rusu L, Arba R. Elder Monitoring Workflow for Independent Living.International Journal of Computers, Communications \& Control. 2018; 13(1):62-70

22. Fischer SH, Daniel David D, Crotty BH, Dierks M, Safran C. Acceptance and Use of Health Information Technology By Community-Dwelling Elders. Int J Med Inform. 2014; 83(9): 624-635.

23. Mocanu I, Rusu L, Sitar-Taut D. Business process analysis for MOBILE@OLD. Conference presented at 9th International Conference on Intelligent Systems and Agents (ISA 2015) At: Las Palmas de Gran Canaria, Spain

24. Morris ME, Adair B, Miller K, Ozanne E, Hampson R, et al. Smart- Home Technologies to Assist Older People to Live Well at Home. Aging Sci; 2013(1):101. 
25. Chen K, Chan AHS. A review of technology acceptance by older adults. Gerontechnology 2011; 10(1):1-12.

26. Demiris G, Hensel BK, Skubic M, Rantz M. Senior residents' perceived need of and preferences for "smart home" sensor technologies. Int J Technol Assess Health Care. 2008;24(1):120-124.

27. Mallenius S, Rossi M, Tuunainen VK (2010) Factors affecting the adoption and use of mobile devices and services by elderly people-results from a pilot study. https://www.researchgate.net/publication/228632076_ Factors_affecting_the_adoption_and_use_of_mobile_ devices_and_services_by_elderly_peopleresults_from_a_pilot_study

28. http://citeseerx.ist.psu.edu/viewdoc/download?doi=10. 1.1.130.2463\&rep=rep1\&type $=$ pdf

29. Mitzner TL, Boron JB, Fausset CB, Adams AE, Charness N, Czaja SJ, Dijkstra K, Fisk AD, Rogers WA, Sharit J. Older adults talk technology: Technology usage and attitudes. Computers in Human Behavior 2010;26(6);1710-1721.

30. Awada IA, Mocanu I, Jecan S, Rusu L, Florea AM, Cramariuc O, Cramariuc B. Mobile@Old - An Assistive platform for maintaining a Healthy Lifestyle for Elderly People. E-Health and Bioengineering Conference (EHB) 2017. https://ieeexplore.ieee.org/document/7995493/

31. Czaja SJ, Charness N, Fisk AD, Hertzog C, Nair SN, Rogers WA, Sharit J. Factors predicting the use of technology: Findings from the Center for Research and Education on Aging and Technology Enhancement (CREATE). Psychology and Aging 2006;21(2);333352.

32. Chung JE, Park N, Wang H, Fulk J, Mclaughlin M. Age differences in perceptions of online community participation among non-users: An extension of the Technology Acceptance Model. Computers in Human Behavior 2010;26(6);1674-1684.

33. Farcas AD, Nastasa LE. Factors influencing the perception of stress in patients with heart failure. Procedia Social and Behavioral Sciences; 2014; 127:144-148.

34. McCloskey DW. The importance of ease of use, usefulness, and trust to online consumers: An examination of the technology acceptance model with older consumers. Journal of Organizational and End User Computing 2006; 18(3);47-65.

35. NITICS consortium, page 4 of 33 Call AAL-2012-5 http://pl.ssw.org.pl/portofolio-view/dolore-magnaaliqua (2013)

36. OLDES AAL program, http://www.oldes.eu/

37. Hera AAL Program http://www.aal-hera.eu/

38. SPES AAL Program, http://www.spes-project.eu/

39. Zao JK, Fan SC, Wen MH, Hsu CT, Hung CH et all. Activity-Oriented Design of Health Pal: A Smart Phone for Elders' Healthcare Support, Hindawi Publishing Corporation, EURASIP Journal on Wireless Communications and Networking, Volume 2008, Article

ID

582194 https://pdfs.semanticscholar.org/4d26/87d1310924c35 50bb8db5e877ffb0195653a.pdf

40. Bodea EE. Researching AAL systems to find the right caracteristics for Mobile@Old project. Proceedings of the IE 2016 International Conference.

41. Steele R, Lo A, Secombe C, Wong YK. Elderly persons' perception and acceptance of using wireless sensor networks to assist healthcare. International Journal of Medical Informatics 2009;78(12);788-801.

42. Ryu MH, Kim S, Lee E. Understanding the factors affecting online elderly user's participation in video UCC services. Computers in Human Behavior 2009;25(3);619-632.

43. Jecan S, Rusu L, Arba R, Mican D. Mobile application for elders with cognitive impairments. Internet Technologies and Applications (ITA) conference 2017 https://ieeexplore.ieee.org/document/8101928/?part=1

44. Jecan S, Arba R, Lucia Rusu L, Mocanu I. Personalized mHealth Monitoring for Elders Using MR@Old. EHealth and Bioengineering Conference (EHB) 2017 HYPERLINK

"https://ieeexplore.ieee.org/document/7995423/"https: //ieeexplore.ieee.org/document/799542 